\author{
KEIO/KYOTO JOINT \\ GLOBAL CENTER OF EXCELLENCE PROGRAM \\ Raising Market Quality-Integrated Design of "Market Infrastructure"
}

KEIO/KYOTO GLOBAL COE DISCUSSION PAPER SERIES

DP2009-011

\title{
AMAKUDARI: THE POST-RETIREMENT EMPLOYMENT OF ELITE BUREAUCRATS IN JAPAN
}

\author{
TETSURO MIZOGUCHI* AND NGUYEN VAN QUYEN**
}

\begin{abstract}
This paper analyzes the amakudari practice in Japan. Amakudari refers to situations where government agencies contact the private firms that they regulate, asking them to provide employment for their retiring elite bureaucrats. Upon employment at the private firms, bureaucrats may collude with their former employers to secure lucrative government contracts, avoid regulatory inspections, or obtain preferential treatment. This paper provides an explicit formalization of the implicit collusion between the regulator and the regulated.
\end{abstract}

\footnotetext{
*TETSURO MIZOGUCHI Faculty of Economics, Keio University

**NGUYEN VAN QUYEN Department of Economics, University of Ottawa
}

\author{
KEIO/KYOTO JOINT GLOBAL COE PROGRAM \\ Raising Market Quality-Integrated Design of "Market Infrastructure" \\ Graduate School of Economics and Graduate School of Business and Commerce, \\ Keio University \\ 2-15-45 Mita, Minato-ku, Tokyo 108-8345, Japan \\ Institute of Economic Research, \\ Kyoto University \\ Yoshida-honmachi, Sakyo-ku, Kyoto 606-8501, Japan
}




\title{
AMAKUDARI: THE POST-RETIREMENT EMPLOYMENT OF ELITE BUREAUCRATS IN JAPAN
}

\author{
$B Y$ \\ TETSURO MizOGUCHI ${ }^{*}$ AND NGUYEN VAN QUYEN**
}

This paper analyzes the amakudari practice in Japan. Amakudari refers to situations where government agencies contact the private firms that they regulate, asking them to provide employment for their retiring elite bureaucrats. Upon employment at the private firms, bureaucrats may collude with their former employers to secure lucrative government contracts, avoid regulatory inspections, or obtain preferential treatment. This paper provides an explicit formalization of the implicit collusion between the regulator and the regulated. (JEL D02, D44, D73)

KEYWORDS: Amakudari, corruption, optimal auction, mechanism design

\footnotetext{
* Faculty of Economics, Keio University, 2-15-45, Mita, Minato-ku, Tokyo 108-0073 (e-mail address: tmizo@econ.keio.ac.jp).

${ }^{* *}$ Department of Economics, University of Ottawa, 55 Laurier Avenue East, Desmarais Building, Ottawa, Ontario, Canada K1N 6N5 (e-mail address: NguyenVan.Quyen@uottawa.ca).

This paper is based on the chapter 2 of Tetsuro Mizoguchi's Ph.D. thesis. We presented the earlier version of this paper at the Annual Conference of the Japanese Economic Association, Tokyo, Japan, September 2007 and Public Economic Workshop at Hitotubashi University, Tokyo Japan, October 2007, the 21st century COE conference at Kyoto University, Kyoto, Japan December 2007, and the Modern Economic Seminar at Yokohama National University, Yokohama, Japan May 2009. We are grateful to Stefan Dodds, Yukihiro Nishimura, Toyotaka Sakai, Motohiro Sato, Naomi Sugie, Yasunari Tamada, Jean-François Tremblay, Makoto Yano and Jiankng Zhang for invaluable comments and discussions on the earlier draft.
} 


\section{INTRODUCTION}

IN THE JAPANESE LANGUAGE, THE TERM AMAKUDARI literally means descent from heaven. In the area of Japanese economic studies - populated mostly by political scientists and sociologists - amakudari describes the reemployment of elite government bureaucrats towards high-ranking positions in the private or quasi-public sector, after the termination of their public service. Although amakudari is very familiar with Japanese people, the internal mechanism of the amakudari process is not explained well from the point of economic literature.

In our paper, we introduce a unique viewpoint from which the amakudari process can be seen - as an equilibrium outcome of the optimal auction run by the ministry. This paper describes the amakudari process within the optimal auction design framework. In the model, there are $\mathrm{N}$ firms, which each differ in their productivities that compete to secure a government contract for a project. The only way for these firms to secure a contract is to employ a retired government official from the ministry, which cares about both the social welfare stemming from the benefit of the completion of the government project and also the remuneration the retired official receives from the firm at the same time.

We consider the amakudari process as the outcome of the optimal auction for the ministry. It illustrates the direct revelation mechanism that maximizes the government agency's expected payoff - a generalized second-price sealed-bid auction - which is Bayesian incentive compatible and also satisfies the interim individual rationality constraints. We show that the ministry's optimal auction creates inefficiency because the most cost-efficient firm will never win the contract. We also conduct some comparative static exercises with regard to the parameters that describe ministry's tastes. 


\subsection{BACKGROUND}

In Japan, each ministry has jurisdiction over particular industrial sectors. Two ministries, the Ministry of Economy, Trade, and Industry (METI) and the Ministry of Finance (MOF), have wide-ranging jurisdictions, and can influence the private sectors through formal and informal controls, such as administrative guidance. For example, METI often requests private firms to subscribe to a variety of cartel-like agreements or to form a cartel themselves to coordinate investment, production, and prices as a means of reducing excessive competition in order to achieve the objectives of their economic plan. ${ }^{1}$

Most of the civil servants who run the Japanese ministries are recruited among top undergraduates from Tokyo University, Japan's highest-ranking university. In the Japanese bureaucracy, promotion is a tournament system. When bureaucrats reach the age of 52 or 53 years old, only a small number of promotion opportunities are open to them, and many bureaucrats are effectively forced to retire. According to Japanese convention, all bureaucrats in a particular recruitment year must retire when one from their cohort is promoted to the vice-minister level in order to consolidate the authority of the newly promoted bureaucrat. Because of this, ministries and agencies arrange new jobs for retiring bureaucrats to unofficially reward their years of service.

The bureaucrats that are most likely to participate in amakudari are former director-generals of ministry bureaus. In their second career, these bureaucrats occupy high-ranking positions in public corporations that work in housing, river works, and road construction. Less prominent bureaucrats, such as former chiefs of regional construction bureaus or councillors at the ministry, commonly find

\footnotetext{
${ }^{1}$ The other ministries include the Ministry of Land, Infrastructure, and Transport, The Ministry of Health, Labor, and Welfare. The functions of the former Ministry of Posts and Telecommunications are now incorporated into the Ministry of Internal Affairs and Communications by their reorganization.
} 
jobs with private construction firms. ${ }^{2}$ Retired bureaucrats generally acquire new employment with companies that have prior relationships with their ministries. For example, during the periods 2004 to 2006 , nearly 70 percent of the 1,968 retired bureaucrats who were helped by their ministries and agencies found employment in companies with close links to their organizations. Of the 1,346 amakudari bureaucrats, more than 500 were from the land ministry, which oversees the construction industry. ${ }^{3}$

Amakudari has been linked to bid-rigging and price-fixing of government projects. Recently, three current and former officials in the Defence Ministry were arrested for allegations concerning the awarding of lucrative contracts to companies that had provided employment to former Defense officials. ${ }^{4}$ In another case, two officials from the Forestry Agency, along with four employees of four contracting firms, were arrested over their alleged involvement in rigging public works projects for the construction of forest roads. ${ }^{5}$ As of 2005, the affiliates had hired 256 former bureaucrats, mostly from the Forestry Agency. In 2003 and 2004, twenty-three bridge builders and a retired Japan Highway Public Corporation official serving as an advisor at one of the firms were implicated in rigged construction bids.

Through its close connection with the financial sector, MOF has been able to find employment for its retiring bureaucrats in private banks. In the past, this practice was often considered as a useful means for supervising and promoting the development of the Japanese banking sector. However, the collapse of the bubble economy in the 1990s has cast doubts on this claim.

\footnotetext{
2 “Amakudari: A Lifeline for Bureaucrats Aged 55 and Up," Posted in We Heart Japan! August 30, 2006, available at http://weheartjapan.com/?p=42

${ }^{3}$ See the article "Amakudari too Entrenched to Curb?" in The Japan Times Online, May 29, 2007 by Hiroko Nakata.

${ }^{4}$ See, for example, the article "Soft Landing Uncertain for Japan's Officials," by David Pilling and Mariko Sanchanta, Financial Times, February 20, 2006.

${ }^{5}$ See the article "Amakudari too Entrenched to Curb?" in The Japan Times Online, May 29, 2007 by Hiroko Nakata.
} 
The research and literature in the English on amakudari is sparse and comes mostly from political scientists and sociologists. ${ }^{6}$ At the theoretical level, the work of Asano and Eto (2003), who formulated a signalling game played between a private bank and its depositors is partially relevant. In their model, the signal represents the decision of the bank about whether or not to employ the service of an amakudari. The model, however, does not contain any strategic interaction between the bank and the regulator. Among the empirical studies, the work of Horiuchi and Shimizu (2001) analyzed the long-term relationships between banks and the government. Using statistical analysis, the authors concluded that the amakudari relationship between the regulator and banks is collusive and weakens the soundness of bank management in Japan. Yamori (1998) used the expensepreference approach developed by Edward (1977) to analyze the impact of amakudari on the Japanese banking system. Suzuki (2004) listed four possible perspectives that purport to explain why a private bank offers a top executive position to a retiring bureaucrat. According to the first perspective, the human capital accumulated by an amakudari - through years of working at the MOF or the Bank of Japan (BOJ) - is highly valued by the private bank. The second perspective stresses the role played by an amakudari as an unsurpassed channel of communications between the firm and the government. This perspective maintains that it is significantly less costly and more effective to communicate with the government via amakudari executives than to access the bureaucracy anonymously from a distance. The third perspective, suggests that amakudari is used as a form of bureaucratic intervention: the presence of retired MOF or BOJ officials on the boards of private banks could be helpful in the implementation of prudential policy. The last perspective on amakudari contends that the process is a system of rewards for bureaucrats who worked long hours at the MOF or the BOJ for several decades at relatively low pay. The main result that emerges from Suzuki's empirical analysis is that amakudari is the practice employed by the MOF and the BOJ to find post-retirement employment for their former employees.

\footnotetext{
${ }^{6}$ See, for example a rather comprehensive analysis of the subject by two sociologists, Colignon and Usui (2003). There is also a limited economic literature in English on the subject.
} 
This conclusion was also reached by van Rixtel (2002, Chapter 8) whose empirical analysis went even farther and suggested that there is collusion between the regulator (MOF) and the regulated (regional private banks). Van Rixtel tested and confirmed the hypothesis that troubled banks are willing to take more risk and are thus more willing to offer amakudari positions to retired MOF bureaucrats, who can use their former connections to persuade supervisory authorities to bend rules and allow them to take risks, such as extending loans to risky industries to restore profitability. According to Asano and Eto (2003, 2005a, 2005b), the rise and collapse of the bubble economy in the mid 1990s has dispelled the belief that amakudari executives have valuable expertise and experience in running the business of a private company and the notion that they are embedded in the private banks to monitor their lending practice in accordance with the prudential principle.

In this paper, we present an analysis of the implicit collusive relationships between government branches and private companies. Although there are rich examples of implicit collusive relationships between government branches and private firms all over the world, we choose to analyze these implicit collusion relationships in the context of the Japanese economy. The amakudari process is not unique to Japan. A similar process - the revolving door - is prevalent in industrialized countries of the West. For example, Drucker (1998) has compared the role of public officials in the private sector in the major developed countries after their retirement. For a description of buying of influence, see Johnston (2005, Chapter 4), where he provides case studies and examples of market-influenced corruption in the United States, Germany and Japan. The model we formulate here can be applied in analyzing the interaction between policy makers and special-interest groups. As such, our analysis contributes to the more general area of economic literature known as influence-buying, pioneered by Grossman and Helpman (2001). 
In this paper, the amakudari process is formalized from the perspective of the theory of the optimal auction design, as developed by Myerson (1981). In the auction, the object offered for sale is the retiring bureaucrat; the seller of the object is the ministry that the retiring bureaucrats previously work for; and the potential buyers are private firms that wish to offer employment to the retiring bureaucrat. For the firms that participate in the auction, the value of the object resides in the fact that the retiring official might collude with his former colleagues to help his new employers secure government contracts, avoid regulatory inspections, and obtain preferential treatment from the bureaucracy. To solidify ideas, and also to accentuate the collusion between the ministry and the private firms that it regulates, we shall assume that the retiring bureaucrat will help the firm at which he lands a job secure a cost plus percentage of cost government contract. Under such a contract, the firm is reimbursed the cost of completing the contract and awarded a percentage of the cost as profit. Because a cost plus percentage of cost contract pays a fee that rises as the costs of the contractor rise, there is no incentive for the contractor to control costs. Furthermore, the more inefficient a contracting firm is, the more profits it will make, and the more it will be able to bribe the public officials who help secure the contract. In addition, the percentage of cost awarded as profit is at the ministry's discretion. ${ }^{7}$ In the auction, the owner of the object - the ministry that was the employer of the retiring bureaucrat - acts as a monopolist and exploits its power to extract bribes, which are the remunerations of the retiring bureaucrat offered by the firm at which he lands an amakudari position. Unlike a revenue-maximizing

\footnotetext{
${ }^{7}$ Because of the severe restrictions it is subject to, The Japanese Defense Ministry orders its procurement from the domestic market primarily through its "cost-plus" contracts Under a cost-plus contract, government contractors like Mitsubishi Heavy Industries are usually reimbursed all those costs from the Central Procurement Office in the Defense Ministry and then paid a percentage of those costs (the plus) as a fee. According to the Defense Ministry, there are two types of the procurement method; the market price method and the cost-plus method. In 2006, the total number of the procurements made by The Defense Ministry is 8,695. The total share of the market price method is $66 \%(5,695)$. On the other hand, the total share of the cost-plus method is $34 \%(2,911)$. But on the pecuniary base, the cost-plus method accounts for $73 \%$ of the total in contrast with the market price method, which accounts for the remaining $27 \%$. Obviously, government contractors earn more profit by wasting taxpayer money. The cost-plus method of accounting is the primary system today for determining how much government contractors are owed by the taxpayer. For more detail, see in the following reference: "About Incentive Contract." by the Inventory-Policy Branch in Defense Ministry (only Japanese version is available).
} 
auction, the ministry that is trying to find employment for its retiring bureaucrat also cares about social welfare in the economy. The ministry's optimal auction represents a trade-off between the welfare of its members and economic efficiency. The results of our analysis suggest that the efforts made by the ministry to find employment and obtain beneficial remuneration for its former employees results in government contracts being awarded to highly inefficient firms.

The remainder of the paper is organized as follows: in Section 2, the formal model of amakudari is presented. The model is solved in Section 3. Properties of the optimal auction are presented in Section 4. Some concluding remarks are given in Section 5.

\section{THE MODEL}

\subsection{Payoffs and Preferences}

To fix ideas, suppose that a government branch, say a ministry, wants to find employment for one of its retiring bureaucrats. In the process, the ministry contacts a number, say $N$, of private firms. For simplicity, assume that the retiring bureaucrat can exploit his ties with the ministry he used to work for to help the firm that offers him employment secure a government contract. Let $x$ be the social value - expressed in terms of the numéraire - of the contract; that is, $x$ represents the social welfare obtained if the contract is completed. Presumably, a highly ranked retiring bureaucrat will obtain a high-value government contract for his new employer. Thus, we can take $x$ as a proxy for the rank of the retiring bureaucrat in the ministry he used to work. The government contract is a cost-plus contract according to which the firm that is awarded the contract is reimbursed the cost of carrying out the project plus a fixed proportion of the cost as profits.

Consider a firm, say firm $i, i \in\{1, \ldots, N\}$, at which the retiring bureaucrat lands a position. The cost that a firm, say firm $i$, must incur to complete a government 
contract is assumed to be a fraction, say $\theta_{i}$, of the social value of the government project. The parameter $\theta_{i}$ can be interpreted as the degree of inefficiency of the firm. If $\tau>0$ is the percentage of cost that the firms is paid as profits after completing the project, then the profit made by the firm is given by $\tau \theta_{i} x$, and the total cost of the government project that the ministry has to pay is $(1+\tau) \theta_{i} x$. We shall assume that for each $i=1, \ldots, N, \theta_{i}$ is firm $i^{\prime} s$ private information and that it is drawn from a distribution, say $\Phi_{i}\left[\theta_{i}\right]$, which is defined on an interval $\Theta_{i}=\left[\underline{\theta}_{i}, \bar{\theta}_{i}\right]$, with $0<\underline{\theta}_{i},<\bar{\theta}_{i}<1$, of the real line. The distribution function $\Phi_{i}\left[\theta_{i}\right]$ is assumed to be common knowledge, and its density $\phi_{i}\left[\theta_{i}\right]$ is assumed to be continuous and strictly positive on $\Theta_{i}$. Also, we assume that the types $\theta_{1}, \ldots, \theta_{N}$ are independent.

A profile of types for the $N$ firms is a list $\theta=\left(\theta_{i}\right)_{i=1}^{N}$, with $\theta_{i} \in \Theta_{i}$ for $i=1, \ldots, N$. An alternative for the group made up of the ministry and the $N$ firms is a list $a=\left(q_{1}, \ldots, q_{N}, b_{1}, \ldots, b_{N}\right)$, where $q_{i}$ and $b_{i}$ denote, respectively, the probability that the retiring bureaucrat lands a position at firm $i$ and the remuneration offered by this firm. Here $q_{i} \geq 0, i=1, \ldots, N$, and $q_{1}+\ldots+q_{N} \leq 1$. In our model, the remuneration $b_{i} \geq 0, i=1, \ldots, N$, can be interpreted as the bribe offered by firm $i$, conditional on the event that it offers the retiring bureaucrat employment. Of course, if this firm is not willing or not able to offer employment to the retiring bureaucrat, then it will pay nothing. The list of alternatives is denoted by $A$.

Under the alternative $a=\left(q_{1}, \ldots, q_{N}, b_{1}, \ldots, b_{N}\right)$, the expected profit of firm $i-$ assuming that it is risk-neutral - is given by

$$
u_{i}\left[a, \theta_{i}\right]=q_{i}\left(\tau \theta_{i} x-b_{i}\right),
$$

As for the ministry, it obviously cares about finding employment as well as the remuneration that it obtains for the retiring bureaucrat. It is also reasonable to 
believe that the ministry cares about economic efficiency. The consumer surplus is then given by $x-(1+\tau) \theta_{i} x$ and the producer surplus by $\tau \theta_{i} x$, for a net social welfare of $x-\theta_{i} x$. We shall assume that the payoff of the ministry is a weighted average of the expected remuneration of the bureaucrat and social welfare. More specifically, the preferences of the ministry are assumed to be represented by the following utility function:

$$
u_{0}[a, \theta]=\sum_{i=1}^{N} q_{i}\left(b_{i}+\varepsilon\left(x-\theta_{i} x\right)\right)
$$

where $\varepsilon \geq 0$ is a parameter representing the weight of social welfare in the utility function of the ministry; the weight of the remuneration being 1 .

The objective of the ministry is to design a mechanism that is Bayesian incentive compatible and that satisfies the interim individual rationality constraints of all the firms to maximize its expected payoff. Note that when $\varepsilon \geq 1$, the ministry cares only about efficiency, and will accept the employment offered by the firm with the lowest expected cost. When $\varepsilon=0$, the utility function of the ministry depends only on the expected remuneration of the retiring bureaucrat, and the problem faced by the ministry is reduced to the traditional problem of designing an auction to maximize the expected revenue. Our model thus can be considered as an extension of the revenue-maximizing auction problem.

\subsection{Amakudari Auction Rule}

In this sub-section, we formalize the process adopted by the ministry in the search of employment for its retiring bureaucrats as a problem in mechanism design.

An Amakudari Auction Rule is a map $f: \prod_{i=1}^{N} \Theta_{i} \rightarrow A$, where the image of each profile of types $\theta \in \prod_{i=1}^{N} \Theta_{i}$ is written as $f[\theta]=\left(q_{1}[\theta], \ldots, q_{N}[\theta], b_{1}[\theta], \ldots, b_{N}[\theta]\right)$. An amakudari auction rule specifies the alternative chosen by the ministry as a function of the profile of types. 
A direct-revelation mechanism is a list $\Gamma=\left(\Theta_{1}, \ldots, \Theta_{N}, f\right)$, where $f$ is an amakudari auction rule. Under the mechanism $\Gamma$, the ministry asks each of the firms to reveal its type. If the announced profile of types is $\theta$, then the ministry implements the alternative $f[\theta]$.

The mechanism $\Gamma$ induces a game of incomplete information in the following manner. For each $i \in\{1, \ldots, N\}$, a strategy for firm $i$ is a map $s_{i}: \Theta_{i} \rightarrow \Theta_{i}$, where $s_{i}\left[\theta_{i}\right]$ is the type announced by firm $i$ when its type is $\theta_{i}$. If $s_{i}\left[\theta_{i}\right]=\theta_{i}$ for each $\theta_{i} \in \Theta_{i}$, then $s_{i}$ is called truth telling. A combination of strategies $\left(s_{i}^{*}\right)_{i=1}^{N}$ constitutes a Bayesian Nash equilibrium for the mechanism $\Gamma$ if for each $i \in\{1, \ldots, N\}$ and each $\theta_{i} \in \Theta_{i}$, the following condition is satisfied:

$$
\int u_{i}\left[f\left[s_{i}^{*}\left[\theta_{i}\right], s_{-i}^{*}\left[\theta_{-i}\right]\right], \theta_{i}\right] d \Phi_{-i}\left[\theta_{-i} \mid \theta_{i}\right] \geq \int u_{i}\left[f\left[\hat{\theta}_{i}, s_{-i}^{*}\left[\theta_{-i}\right]\right], \theta_{i}\right] d \Phi_{-i}\left[\theta_{-i} \mid \theta_{i}\right]
$$

for all $\hat{\theta}_{i} \in \Theta_{i}$.

In (3), we have used the following convention: $\theta_{-i}=\left(\theta_{1}, \ldots, \theta_{(i-1)}, \theta_{(i+1)}, \ldots, \theta_{N}\right)$, and $\Phi_{-i}\left[\theta_{-i}\right]$ is the distribution function of $\theta_{-i}$. Also, $s_{-i}=\left(s_{1}, \ldots, s_{(i-1)}, s_{(i+1)}, \ldots, s_{N}\right)$ represents the lists of strategies of the firms other than the ith firm. If $\left(s_{i}^{*}\right)_{i=1}^{N}$ are all truth-telling, then the amakudari auction rule $f$ is said to be truthfully implementable in Bayesian Nash equilibrium (or Bayesian incentive compatible).

Without some appropriate restrictions on $f$, the direct revelation mechanism will not work. First, there is no a priori reason to believe that the firms will reveal truthfully their types. Under such a scenario, the profile of types, say $\theta$, announced by the agents $1, \ldots, N$ might not be the true profile of types, and the alternative $f[\theta]$ will not be the one the ministry wishes to implement. Second, a 
firm will not participate in the process unless it obtains at least its reservation payoff. In the parlance of mechanism design, the ministry can only successfully implement the amakudari auction rule $f$ if this function is Bayesian incentive compatible and satisfies the interim rationality constraint for each of the firms.

Now let $\Gamma=\left(\Theta_{1}, \ldots, \Theta_{N}, f\right)$ be a direct revelation mechanism. For each $i \in\{1, \ldots, N\}$ and each $\hat{\theta}_{i} \in \Theta_{i}$, let

$$
\bar{b}_{i}\left[\hat{\theta}_{i}\right]=\int q_{i}\left[\hat{\theta}_{i}, \theta_{-i}\right] b_{i}\left[\hat{\theta}_{i}, \theta_{-i}\right] d \Phi_{-i}\left[\theta_{-i}\right],
$$

and

$$
\bar{q}_{i}\left[\hat{\theta}_{i}\right]=\int q_{i}\left[\hat{\theta}_{i}, \theta_{-i}\right] d \Phi_{-i}\left[\theta_{-i}\right]
$$

As defined, $\bar{b}_{i}\left[\hat{\theta}_{i}\right]$ represents the expected remuneration offered by firm $i$ under the mechanism $\Gamma$, given that it announces $\hat{\theta}_{i}$ as its type and all the other firms announce their types truthfully. As for $\bar{q}_{i}\left[\hat{\theta}_{i}\right]$, it represents the probability that the retiring bureaucrat lands a position at firm $i$, given that the firm announces $\hat{\theta}_{i}$ as its type and all the other firms announce their types truthfully.

The expected profit of firm $i$ under the direct revelation mechanism $\Gamma$, given that it announces $\hat{\theta}_{i}$ as its type and all the other firms reveal truthfully their types, is then given by $\bar{q}_{i}\left[\hat{\theta}_{i}\right] \tau \theta_{i} x-\bar{b}_{i}\left[\hat{\theta}_{i}\right]$. If the type of firm $i$ is $\theta_{i}$ and if all the firms firm $i$ included - reveal their types truthfully, then the expected profit of this firm is given by

$$
U_{i}\left[\theta_{i}\right]=\bar{q}_{i}\left[\theta_{i}\right] \tau \theta_{i} x-\bar{b}_{i}\left[\theta_{i}\right]
$$

The following lemma, which is a restatement of Proposition 23.D.2 in Mas-Collel, Whinston, and Green (1995), gives necessary and sufficient conditions for an amakudari auction rule to be Bayesian incentive compatible. 
LEMMA: An amakudari auction rule

$$
f: \theta \rightarrow f[\theta]=\left(q_{1}[\theta], \ldots, q_{N}[\theta], b_{1}[\theta], \ldots, b_{N}[\theta]\right)
$$

is Bayesian incentive compatible if and only if for each $i \in\{1, \ldots, N\}$,

(i) $\bar{q}_{i}: \theta_{i} \rightarrow \bar{q}_{i}\left[\theta_{i}\right]$ is non-decreasing, and

(ii) $U_{i}\left[\theta_{i}\right]=U_{i}\left[\underline{\theta}_{i}\right]+\tau x \int_{\underline{\theta}_{i}}^{\theta_{i}} \bar{q}_{i}[t] d t$ for all $\theta_{i} \in \Theta_{i}$.

Now if firm $i$ does not participate in the direct revelation mechanism $\Gamma$, then its payoff is 0 . The direct revelation mechanism $\Gamma$ is said to satisfy the interim individual rationality constraints if for each $i=1, \ldots, N$,

$$
U_{i}\left[\theta_{i}\right] \geq 0 \text {, for all } \theta_{i} \in \Theta_{i} .
$$

\subsection{The Problem of the Ministry}

The problem of the ministry is to find an amakudari auction rule that is Bayesian incentive compatible and that satisfies the interim individual rationality constraints to maximize its expected payoff. To this end, let

$$
f: \theta \rightarrow f[\theta]=\left(q_{1}[\theta], \ldots, q_{N}[\theta], b_{1}[\theta], \ldots, b_{N}[\theta]\right)
$$

be an amakudari auction rule that satisfies both of these rationality constraints. The expected payoff of the ministry under the direct revelation mechanism $\Gamma=\left(\Theta_{1}, \ldots, \Theta_{N}, f\right)$ is

$$
\int u_{0}[f[\theta], \theta] d \Phi[\theta]=\sum_{i=1}^{N} \int q_{i}[\theta] b_{i}[\theta] d \Phi[\theta]+\varepsilon \sum_{i=1}^{N} \int q_{i}[\theta]\left(x-\theta_{i} x .\right) d \Phi[\theta] .
$$

A long series of calculations can yield the following expression for the expected remuneration of the retiring bureaucrat: 


$$
\begin{aligned}
& \sum_{i=1}^{N} \int q_{i}[\theta] b_{i}[\theta] d \Phi(\theta)= \\
& \tau x \int_{\underline{\theta}_{1}}^{\bar{\theta}_{1}} \ldots \int_{\underline{\theta}_{N}}^{\bar{\theta}_{N}}\left(\sum_{i=1}^{N} q_{i}\left[\theta_{1}, \ldots, \theta_{N}\right]\left(\theta_{i}-\frac{1-\Phi_{i}\left[\theta_{i}\right]}{\phi_{i}\left[\theta_{i}\right]}\right)\right)\left(\prod_{j=1}^{N} \phi_{j}\left[\theta_{j}\right]\right) d \theta_{N} \ldots d \theta_{1} \\
& \quad-\sum_{i=1}^{N} U_{i}\left[\underline{\theta}_{i}\right] .
\end{aligned}
$$

Using (6) in (5), we can rewrite the expected payoff for the ministry under the amakudari auction rule $f$ as follows:

$$
\begin{aligned}
& \int u_{0}[f[\theta], \theta] d \Phi[\theta]=-\sum_{i=1}^{N} U_{i}\left[\underline{\theta}_{i}\right]+ \\
& \quad x \int_{\underline{\theta}_{1}}^{\bar{\theta}_{1}} \ldots \int_{\underline{\theta}_{N}}^{\bar{\theta}_{N}}\left(\sum_{i=1}^{N} q_{i}\left[\theta_{1}, \ldots, \theta_{N}\right] J_{i}\left[\theta_{i}\right]\right) \prod_{j=1}^{N} \phi_{j}\left[\theta_{j}\right] d \theta_{N} \ldots d \theta_{1},
\end{aligned}
$$

where we have let

$$
J_{i}\left[\theta_{i}\right]=\varepsilon\left(1-\theta_{i}\right)+\tau\left(\theta_{i}-\frac{1-\Phi_{i}\left[\theta_{i}\right]}{\phi_{i}\left[\theta_{i}\right]}\right) .
$$

The problem faced by the ministry is to find an amakudari auction rule $f$ that is Bayesian incentive compatible and satisfies the interim individual rationality constraints to maximize (7).

Although the expression $\tau\left(\theta_{i}-\left(1-\Phi_{i}\left[\theta_{i}\right]\right) / \phi_{i}\left[\theta_{i}\right]\right)$ looks a little strange, especially to a reader who is not familiar with recent developments in auction theory, it can be interpreted as the marginal revenue obtained by a monopolist in a market when he practices third-degree price discrimination ${ }^{8}$ Under this interpretation, and for a government project of social value 1, the expression $J_{i}\left[\theta_{i}\right]$, which is a weighted average of social welfare and bribe, can be interpreted as the marginal contribution of firm $i$ in the payoff of the ministry. To gain some

\footnotetext{
${ }^{8}$ See Bulow and Roberts (1989), who demonstrated that the seller's problem in designing an optimal auction is virtually identical to the third-degree price discrimination problem in monopoly.
} 
understanding of the economic content of $J_{i}\left[\theta_{i}\right]$, let us consider the special case of $N=1$. In this simple case, the ministry can post a bribe, say $b$, and then let the firm decide whether or not to offer employment to the retiring bureaucrat. Given $b$, the firm will only agree to offer employment to the retiring bureaucrat if the bribe is lower than its valuation of the retiring bureaucrat, i.e., only if $\tau \theta x>b$, or equivalently only if $\theta>b /(\tau x)$. Hence the expected payoff of the ministry is

$$
\begin{aligned}
\int_{b /(\not x)}^{\bar{\theta}}(b+\varepsilon(x-\theta x) \phi[\theta] d \theta=b(1- & \Phi[b /(\tau x)]) \\
& +\int_{b /(x)}^{\bar{\theta}} \varepsilon(x-\theta x) \phi[\theta] d \theta .
\end{aligned}
$$

The problem of the ministry is to find the bribe that maximizes the preceding expected payoff. The following first-order condition characterizes the optimal bribe:

$$
1-\Phi\left[\frac{b}{\tau x}\right]-\frac{b}{\tau x} \phi\left[\frac{b}{\tau x}\right]-\frac{\varepsilon\left(x-x \frac{b}{\tau x}\right)}{\tau x} \phi\left[\frac{b}{\tau x}\right]=0
$$

If we let $b^{+}$denote the value of $b$ that solves this first-order condition, and $\theta^{+}=b^{+} /(\tau x)$, then the preceding first-order condition becomes

$$
1-\Phi\left[\theta^{+}\right]-\theta^{+} \phi\left[\theta^{+}\right]-\frac{\varepsilon\left(x-\theta^{+} x\right)}{\tau x} \phi\left[\theta^{+}\right]=0,
$$

which can be rewritten as follows

$$
x\left(\varepsilon\left(1-\theta^{+}\right)+\tau\left(\theta^{+}-\frac{1-\Phi\left[\theta^{+}\right]}{\phi\left[\theta^{+}\right]}\right)\right) \phi\left[\theta^{+}\right]=0,
$$

i.e., $J\left[\theta^{+}\right]=0$. Furthermore, if we assume that $J[\theta]$ is increasing in $\theta$, then the firm will agree to pay the bribe only if $\theta>\theta^{+}$, and this is exactly the solution of the problem of maximizing (7) for the case $N=1$. 


\section{THE OPTIMAL AUCTION}

To find the optimal auction for the ministry, let $\theta=\left(\theta_{1}, \ldots, \theta_{N}\right)$ be a profile of types announced by the $N$ firms, and consider the following constrained maximization problem:

(9) $\quad \max _{\left(q_{1}, \ldots, q_{N}\right)} \sum_{i=1}^{N} q_{i} J_{i}\left[\theta_{i}\right]$

subject to

$$
q_{i} \geq 0, i=1, \ldots, N, \text { and } q_{1}+\ldots+q_{N} \leq 1 .
$$

The solution of this constrained maximization problem is given by

$$
q_{i}^{*}[\theta]=\left\{\begin{array}{l}
1 \text { if } J_{i}\left[\theta_{i}\right]=\max \left\{J_{1}\left[\theta_{1}\right], \ldots, J_{N}\left[\theta_{N}\right]\right\} \text { and } J_{i}\left[\theta_{i}\right]>0 \\
0, \text { otherwise. }
\end{array}\right.
$$

In the event that more than one firm has the maximum marginal contribution, and if the maximum marginal contribution is positive, break the tie by setting $q_{i}^{*}[\theta]=1$ for the firm with the smallest index $i \in\{1, \ldots, N\}$. Because for each $i=1, \ldots, N$, the density function $\phi_{i}\left[\theta_{i}\right], \underline{\theta}_{i} \leq \theta_{i} \leq \bar{\theta}_{i}$, is continuous and strictly positive, the set of type profiles $\theta$ such that $J_{i}\left[\theta_{i}\right]=J_{j}\left[\theta_{j}\right]$ for two firms $i, j$, with $i \neq j$, has probability 0 , which implies that except for a set of type profiles of probability 0 , there is only one index $i \in\{1, \ldots, N\}$ such that $J_{i}\left[\theta_{i}\right]=\max \left\{J_{1}\left[\theta_{1}\right], \ldots, J_{N}\left[\theta_{N}\right]\right\}$.

In what follows, we shall make the following assumption:

ASSUMPTION: For each $i=1, \ldots, N$, (i) $J_{i}\left[\theta_{i}\right], \underline{\theta}_{i} \leq \theta_{i} \leq \bar{\theta}_{i}$, is increasing, and (ii) $J_{i}\left[\underline{\theta}_{i}\right]<0$. 
Assumption (i) expresses the intuitive idea that the higher the profit made by firm $i$ if it obtains the government project, the higher will be its marginal contribution in the ministry's expected payoff. In the context of third-degree price discrimination, this is the assumption that the marginal revenue in each market is decreasing in quantity, or, equivalently, increasing in price. Now if the density function $\phi_{i}\left[\theta_{i}\right]$ is log-concave, ${ }^{9}$ then the failure rate $\phi_{i}\left[\theta_{i}\right] /\left(1-\Phi_{i}\left[\theta_{i}\right]\right)$ is increasing in $\theta_{i}$. The failure rate is also increasing if the density function $\phi_{i}\left[\theta_{i}\right]$ is increasing. Hence if $\varepsilon \leq \tau$ and if the failure rate $\phi_{i}\left[\theta_{i}\right] /\left(1-\Phi_{i}\left[\theta_{i}\right]\right)$ is increasing in $\theta_{i}$, then (i) is satisfied. Assumption (ii) embodies the presumption that if the profit that firm $i$ makes from the government contract is at the low end of its type distribution, then the marginal contribution that it brings to the auction will be negative. This assumption can be justified by assuming that $\phi_{i}\left[\underline{\theta}_{i}\right]$ is small, i.e., if the probability that the type of firm $i$ is most efficient in exploiting its technology is very small. Note that the marginal contribution of firm $i$ when it is most inefficient in exploiting its technology is $J_{i}\left[\bar{\theta}_{i}\right]=\varepsilon\left(1-\bar{\theta}_{i}\right)+\tau \bar{\theta}_{i}>0$. This last result together with the assumption imply that there exist a unique value of $\theta_{i}$, say $\theta_{i}=\theta_{i}^{+}$, that solves $J_{i}\left[\theta_{i}\right]=0$. We shall call $\theta_{i}^{+}$the threshold degree of inefficiency of firm $i$. For the ministry, a firm with a degree of inefficiency that is below its threshold level has negative marginal contribution, and will be excluded from the auction.

To implement the mechanism that maximizes its expected payoff, the ministry can use the following procedure. First, ask each firm to reveal its type. Next, for each $i \in\{1, \ldots, N\}$, compute $J_{i}\left[\theta_{i}\right]$ from the value of $\theta_{i}$ revealed by firm $i$. The probability of winning the bid for each firm is given by (11). More specifically, the firm with the highest marginal contribution is the winner of the auction. As for the bribe extracted from each firm, it is given by

\footnotetext{
${ }^{9}$ See Bergstrom and Bagnoli (2005).
} 


$$
b_{i}^{*}[\theta]=\left\{\begin{array}{l}
\tau \mathrm{x}\left(\min \left\{t \in \Theta_{i} \mid J_{i}(t) \geq \max \left\{0, J_{-i}[\theta]\right\}\right\}\right) \text { if } q_{i}^{*}[\theta]=1 \\
0, \text { otherwise. }
\end{array}\right.
$$

In (12), we have let $J_{-i}[\theta]=\left(J_{j}\left[\theta_{j}\right]\right)_{j \neq i}$. According to (12), a firm that does not win the bid pays nothing. For the firm that wins the bid, the remuneration it offers to the bureaucrat is not the entire profit it makes from the government project, but the level that corresponds to the lowest degree of inefficiency that it could have announced without losing the bid, given the types announced by the other firms.

Now let $f^{*}: \prod_{i=1}^{N} \Theta_{i} \rightarrow A$ be the amakudari auction rule defined by

$$
f^{*}[\theta]=\left(q_{1}^{*}[\theta], \ldots, q_{N}^{*}[\theta], b_{1}^{*}[\theta], \ldots, b_{N}^{*}[\theta]\right) .
$$

Proposition 1: Suppose that for each $i \in\{1, \ldots, N\}$ the marginal contribution function $J_{i}\left[\theta_{i}\right], \underline{\theta}_{i} \leq \theta_{i} \leq \bar{\theta}_{i}$, is increasing and satisfies the inequality $J_{i}\left[\underline{\theta}_{i}\right]<0$. Then the direct revelation mechanism $\Gamma^{*}=\left(\Theta_{1}, \ldots, \Theta_{N}, f^{*}\right)$, where $f^{*}$ is defined by (11), (12), and (13), is a generalized second-price sealed-bid auction in which truth telling is a weakly dominant strategy for each firm. This direct revelation mechanism maximizes the expected payoff of the ministry among the class of direct revelation mechanisms that are Bayesian incentive compatible and that satisfy the interim individual rationality constraints.

ProOF: See Appendix A.

\section{PROPERTIES OF THE AMAKUDRI AUCTION}

The following proposition gives a characterization of the ministry's optimal auction.

PROPOSITION 2: The ministry's optimal amakudari auction is not socially efficient. First, it excludes a firm with cost near the low end of its type distribution. Second, 
if the firms are symmetric, and if the degree of inefficiency of at least one firm exceeds its threshold level, it awards the bid to the firm with the highest cost. Third, when the firms are asymmetric, the optimal auction discriminates against them by awarding the prize, not to the firm with the highest cost, but to the firm with the highest marginal contribution. The discrimination helps to maximize the expected payoff of the ministry.

PROOF: According to the optimal auction, a firm with a degree of inefficiency that is lower than the threshold level is excluded from the bid. That is, if $\theta_{i} \leq \theta_{i}^{+}$, then firm $i$ is excluded from the auction. The optimal auction discriminates against a firm when the firm is most efficient in exploiting its own technology. In particular, when the degree of inefficiency of each firm does not exceed the threshold level, none of them will be awarded the bid, and this event has probability $\prod_{i=1}^{N} \Phi_{i}\left[\theta_{i}^{+}\right]>0$

When the degree of inefficiency of at least one firm exceeds its threshold level, the optimal auction awards the bid to the firm with the highest marginal contribution. If all the firms are symmetric, then the firm with the highest marginal contribution is also the one with the highest cost. In this case, it is at the firm that is most inefficient that the retiring bureaucrat lands a job. When the firms are not symmetric, the firm that wins the bid might not be the one with the highest cost. However, this result is only a consequence of the decision of the ministry to practice third-degree price discrimination in its efforts to extract from the firms as much remuneration as possible for the retiring bureaucrat, while also caring to some degree about social welfare.

The economic intuition behind Proposition 2 is not hard to grasp. Under a costplus-a-percentage-of-cost contract, the more inefficient a firm is, the more profits it makes, and, therefore, the higher the remuneration it is willing to offer to the 
retiring bureaucrat. Such a firm is favored by the ministry in its effort to find a highly remunerative position for the retiring bureaucrat.

Now because the value of the government contract that the retiring bureaucrat helps secure for the firm that offers him employment can be taken as a proxy for his rank in the ministry he used to work, we expect that a high-ranking retiring bureaucrat will command a high remuneration. The following proposition confirms this intuition.

PROPOSITION 3: For each profile of types, the remuneration of the retiring bureaucrat is proportional to the value of the government project that he can help secure for the firm at which he lands a job. Loosely speaking, the higher the rank of the retiring bureaucrat in the former ministry that he used to work, the higher will be the remuneration he receives in his second career.

PROOF: According to the optimal auction, $J_{i}\left[\theta_{i}\right]$ does not depend on the value of the government contract that the retiring bureaucrat might help secure for the firm that offers him employment. Furthermore, according to (12), the remuneration offered by the firm that wins the bid is proportional to the value of the government contract.

The two parameters $\varepsilon$ and $\tau$ are set at the discretion of the ministry. Because the weight for the remuneration of the retiring bureaucrat is 1 , the value of $\varepsilon$ set by the ministry indirectly reflects its valuation of the retiring bureaucrat. If the ministry considers a retiring bureaucrat as being very important, it will set a low value for $\varepsilon$. The following proposition, which is proved in Appendix B, describes the effect of a rise in the weight assigned to the welfare component in the ministry's payoff.

Proposition 4: $A$ rise in the weight assigned to the welfare component in the preferences of the ministry, 
(i) lowers the threshold degree of inefficiency of each firm;

(ii) raises net social welfare uniformly for all type profiles; and

(iii) lowers the expected remuneration of the retiring bureaucrat.

The economic intuition behind Proposition 4 is simple. When the ministry raises the weight it assigns to the welfare component, it shifts the trade-off between welfare and remuneration in favor of the former component. The shift takes the form of a lower threshold of inefficiency degree for each firm to allow more of them to participate in the auction. For all type profiles, net social welfare rises because the shift allows a firm with a lower degree of inefficiency to win the bid. The trade-off in favor of social welfare obviously implies a lower expected remuneration for the retiring bureaucrat.

The following proposition, which is proved in Appendix C, describes the effect of a rise in $\tau$, the profit - as a percentage of cost - earned by the firm that wins the bid.

PROPOSITION 5: A rise in the percentage of cost awarded as profit to the firm that wins the bid

(i) raises the threshold degree of inefficiency of each firm;

(ii) lowers net social welfare uniformly for all type profiles, and

(iii) raises the expected remuneration of the retiring bureaucrat.

The economic intuition behind Proposition 5 is a little more subtle than that behind Proposition 4 . When the ministry raises the percentage of cost awarded as profits, it raises the profits of the firm that wins the bid to offer employment to the retiring bureaucrat. The higher profits allow the firm to offer the retiring bureaucrat a higher remuneration, inducing a shift in favor of the bribe component in the preferences of the ministry, and this explains the decline in net social welfare. The shift also manifests itself under the form of a higher threshold degree of inefficiency for each firm, and this raises the expected remuneration of the 
retiring bureaucrat. Now only highly inefficient firms, i.e., firms which can pay higher bribes, will be allowed to bid for the service of the retiring bureaucrat.

\section{CONCLUSION}

In this paper, we have introduced the idea that the amakudari process is a form of institutionalized corruption. Amakudari can be viewed as a process of the equilibrium outcomes of optimal auctions run by the ministry. However, there are more favourable, alternative views on amakudari. Until recently, many occidental scholars have claimed that the process contributes to the miraculous economic development of Japan after the World War II. ${ }^{10}$ From the perspective of political science, our analysis supports the theory of the elite equalization of Calder (1989). Private companies in local areas regard ex-bureaucrats as coordinators and intermediaries that are able to access the central government. These private companies employ amakudari bureaucrats to make connections with the central government - a form of elite equalization - to level the playing field in the competition with larger firms. When a company offers a high remuneration position to the ministry, we can expect that its operation is in serious trouble. An amakudari position that it offers to a retiring bureaucrat serves as a means to avoid regulatory inspections. In that sense, our model introduces a certain view for the collusive interaction between bad loans of local banks and the central government as Horiuchi and Shimizu (2001) analyzed empirically. At a less exalted level, the amakudari process - according to the view of efficient corruption $^{11}$ which views collusion as a way to "grease the wheels" - helps to reduce the various transaction costs faced by private companies through bribery in the context of public procurements.

The amakudari practice is regularly denounced in the popular press, and attempts have been made by the government to curb this practice. However, this is a

\footnotetext{
${ }^{10}$ There are several discussions about Japanese miracle economic growth after the War. For interested reader, see Komiya et al (1988).

${ }^{11}$ See "Economic Analysis of Corruption: A Survey," by Aidt (2003).
} 
problem without an easy solution because the political system relies heavily on bureaucrats for policymaking. When the Diet is in session, young bureaucrats in Kasumigaseki, Tokyo's civil service center, work day and night to prepare answers used by Cabinet ministers to respond to questions posed by opposition lawmakers. Most bureaucrats believe that an amakudari position represents deferred compensation for the long hours they put in and the low salary they received earlier in their careers. Politicians fear that shutting down the practice could result in an immediate mass exodus of civil servants to the private sector and reduce the incentive for Japan's best and brightest to join the civil service. This is not a problem that is unique to Japan. In industrialized countries of the West, it is often asserted that the low pay received by public officials discourages talent from entering the public sector.

\section{APPENDIX A}

\section{PROOF OF PROPOSITION 1}

The direct revelation mechanism $\Gamma^{*}=\left(\Theta_{1}, \ldots, \Theta_{N}, f^{*}\right)$ is a generalized second price sealed-bid auction in which the firm with the highest marginal contribution - if the highest marginal contribution is positive - is awarded the privilege of offering employment to the retiring bureaucrat. In this mechanism, truth telling is a weakly dominant strategy for each firm. Indeed, if a firm wins the bid, then overstating its type still allows it to win the bid. However, the remuneration it has to offer to the retiring bureaucrat is still the same. Thus overstating its type under this scenario does not improve the firm's payoff. If the firm understates its type and still wins the bid, then the remuneration it has to offer to the retiring bureaucrat is still the same. However, if the firm understates its type substantially, it might lose the bid and earns nothing. Thus understating its type does not improve its payoff under this scenario, either. If the firm does not win when it truthfully reveals its type, then understating its type obviously still does not allow the firm to win the bid. Overstating its type might allow the firm to win the bid, but at a price that exceeds the profit it earns from the government contract that the 
retiring bureaucrat helps secure. Hence the firm will not improve its payoff either by overstating or understating its type; that is, truth telling is a weakly dominant strategy for each firm, and the mechanism $\Gamma^{*}=\left(\Theta_{1}, \ldots, \Theta_{N}, f^{*}\right)$ is thus Bayesian incentive compatible.

Next, note that due to the assumption $J_{i}\left[\theta_{i}\right]<0$, a firm is excluded from the auction if its type is at its lowest possible value. Hence $U_{i}^{*}\left[\underline{\theta}_{i}\right]=0, i=1, \ldots, N$; that is, the expected payoff for each firm under the mechanism $\Gamma^{*}=\left(\Theta_{1}, \ldots, \Theta_{N}, f^{*}\right)$ is 0 when its type is at the low end of the type distribution. The amakudari auction rule $f^{*}$ satisfies the interim individual rationality constraints. Under the amakudari auction rule $f^{*}$, the expected payoff for the ministry is

$$
x \int_{\underline{\underline{\theta}}_{1}}^{\bar{\theta}_{1}} \ldots \int_{\underline{\theta}_{N}}^{\bar{\theta}_{N}}\left(\sum_{i=1}^{N} q_{i}^{*}\left[\theta_{1}, \ldots, \theta_{N}\right] J_{\mathrm{i}}\left[\theta_{i}\right]\right) \prod_{j=1}^{N} \phi_{j}\left[\theta_{j}\right] d \theta_{N} \ldots d \theta_{1},
$$

which is clearly greater than (7). Hence $f^{*}$ maximizes the ministry's expected payoff among the class of amakudari auction rules that are Bayesian incentive compatible and that satisfy the interim individual rationality constraints.

\section{APPENDIX B}

\section{PROOF OF PROPOSITION 4}

To study the influence of the weight of the welfare component in the preferences of the ministry on the optimal auction, we now make explicit the dependence of the marginal contribution of each firm on $\varepsilon$ by writing it as

$$
J_{i}\left[\theta_{i} \mid \varepsilon\right]=\varepsilon\left(1-\theta_{i}\right)+\tau\left(\theta_{i}-\frac{1-\Phi_{i}\left[\theta_{i}\right]}{\phi_{i}\left[\theta_{i}\right]}\right), \quad(i=1, \ldots, N) .
$$

The value of $\theta_{i}$ that solves $J_{i}\left[\theta_{i} \mid \varepsilon\right]=0$ is now noted $\theta_{i}^{+}[\varepsilon]$, and the probability that a firm wins the bid under a type profile $\theta=\left(\theta_{i}\right)_{i=1}^{N}$ is now noted as $q_{i}^{*}[\theta \mid \varepsilon], i=1, \ldots, N$. 
Let $H[\varepsilon]$ denote the set that consists of all type profiles $\theta=\left(\theta_{i}\right)_{i=1}^{N}$ such that $\theta_{i}>\theta_{i}^{+}[\varepsilon]$ for some $i$. For a type profile $\theta \in H[\varepsilon]$, the marginal contribution of at least one firm is positive, and thus $q_{i}^{*}[\theta \mid \varepsilon]=1$ for some $i$. For a type profile $\theta \notin H[\varepsilon]$, the marginal contribution of each firm is less than or equal to 0 , and thus $q_{i}^{*}[\theta \mid \varepsilon]=0$ for each $i=1, \ldots, N$.

CLAIM 1: A rise in the weight of the welfare component lowers the threshold degree of inefficiency of each firm.

PROOF: Because $\theta_{i} \leq \bar{\theta}_{i}<1$, a rise in $\varepsilon$ will shift the curve $\theta_{i} \rightarrow J_{i}\left[\theta_{i} \mid \varepsilon\right], \underline{\theta}_{i} \leq \theta_{i} \leq \bar{\theta}_{i}$, upward, and this will lower the threshold degree of inefficiency for firm $i$. Thus a rise in $\varepsilon$ will lower $\theta_{i}^{+}[\varepsilon]$ for each $i=1, \ldots, N$.

ClaIM 2: For each profile of types $\theta=\left(\theta_{i}\right)_{i=1}^{N}$ with $\theta_{i}>\theta_{i}^{+}\left[\varepsilon_{1}\right]$ for some $i$, a rise in the weight of the welfare component raises net social welfare.

PROOF: Suppose that the weight of the welfare component rises from $\varepsilon_{1}$ to $\varepsilon_{2}$. According to Claim 1, $\theta_{i}^{+}\left[\varepsilon_{2}\right]<\theta_{i}^{+}\left[\varepsilon_{1}\right], i=1, \ldots, N$. Hence $H\left[\varepsilon_{1}\right] \subset H\left[\varepsilon_{2}\right]$. Consider a profile of types $\theta=\left(\theta_{i}\right)_{i=1}^{N}$ in $H\left[\varepsilon_{1}\right]$. Let $j$ be the firm that wins the bid under this profile of types when $\varepsilon_{1}$ is the weight of the welfare component. In this case, the net social welfare is $x-\theta_{j} x$. For the same profile of types, if this firm still wins the bid when the weight for the welfare component is $\varepsilon_{2}$, then the net social welfare does not change when the weight for the welfare component rises from $\varepsilon_{1}$ to $\varepsilon_{2}$. If a different firm, say firm $i$, wins the bid when the weight for the welfare component is $\varepsilon_{2}$, then we must have 
(B.1) $\varepsilon_{2}\left(1-\theta_{i}\right)+\tau\left(\theta_{i}-\frac{1-\Phi_{i}\left[\theta_{i}\right]}{\phi_{i}\left[\theta_{i}\right]}\right) \geq \varepsilon_{2}\left(1-\theta_{j}\right)+\tau\left(\theta_{j}-\frac{1-\Phi_{j}\left[\theta_{j}\right]}{\phi_{j}\left[\theta_{j}\right]}\right)$,

with $i<j$ when equality holds in (B.1).

Because firm $j$ wins the bid when the weight for the welfare component is $\varepsilon_{1}$, the following inequality must also hold

$$
\varepsilon_{1}\left(1-\theta_{i}\right)+\tau\left(\theta_{i}-\frac{1-\Phi_{i}\left[\theta_{i}\right]}{\phi_{i}\left[\theta_{i}\right]}\right) \leq \varepsilon_{1}\left(1-\theta_{j}\right)+\tau\left(\theta_{j}-\frac{1-\Phi_{j}\left[\theta_{j}\right]}{\phi_{i}\left[\theta_{j}\right]}\right),
$$

with $j<i$ when equality holds in (B.2).

Because $i<j$ and $j<i$ cannot hold at the same time, either inequality (B.1) or inequality (B.2) must be strict. Subtracting (B.2) from (B.1), we obtain

(B.3) $\left(\varepsilon_{2}-\varepsilon_{1}\right)\left(1-\theta_{i}\right)>\left(\varepsilon_{2}-\varepsilon_{1}\right)\left(1-\theta_{j}\right)$,

which implies that $\theta_{i}<\theta_{j}$; that is, for the same profile of types net social welfare is higher when the weight for the welfare component is $\varepsilon_{2}$. We have just shown that for a profile of types $\theta=\left(\theta_{i}\right)_{i=1}^{N}$ in $H\left[\varepsilon_{1}\right]$, social welfare rises when the weight of the welfare component rises. For a profile of type in $H\left[\varepsilon_{2}\right]-H\left[\varepsilon_{1}\right]$, the government project will be carried out when the weight of the welfare component is $\varepsilon_{2}$, but not when it is $\varepsilon_{1}$, and thus welfare rises when the weight of the welfare component rises from $\varepsilon_{1}$ to $\varepsilon_{2}$. For the type profiles that are not in $H\left[\varepsilon_{2}\right]$, the government project is not carried out before or after the rise in the weight of the welfare component.

CLAIM 3: A rise in the weight of the welfare component reduces the expected remuneration of the retiring bureaucrat.

PROOF: When the weight of the welfare component is $\varepsilon_{1}$, the expected remuneration of the retiring bureaucrat - according to (6) - is given by 


$$
\omega\left[\varepsilon_{1}\right]=\tau x \int_{H\left[\varepsilon_{1}\right]}\left(\sum_{i=1}^{N} q_{i}^{*}\left[\theta \mid \varepsilon_{1}\right]\left(\theta_{i}-\frac{1-\Phi_{i}\left[\theta_{i}\right]}{\phi_{i}\left[\theta_{i}\right]}\right)\right) \prod_{j=1}^{N} \phi_{j}\left[\theta_{j}\right] d \theta_{N} \ldots d \theta_{1} .
$$

When the weight of the welfare component is $\varepsilon_{2}$, the expected remuneration of the retiring bureaucrat is given by

$$
\begin{gathered}
\omega\left[\varepsilon_{2}\right]=\approx x \int_{H\left[\varepsilon_{2}\right]}\left(\sum_{i=1}^{N} q_{i}^{*}\left[\theta \mid \varepsilon_{2}\right]\left(\theta_{i}-\frac{1-\Phi_{i}\left[\theta_{i}\right]}{\phi_{i}\left[\theta_{i}\right]}\right)\right) \prod_{j=1}^{N} \phi_{j}\left[\theta_{j}\right] d \theta_{N} \ldots d \theta_{1} \\
=M_{1}+M_{2}
\end{gathered}
$$

where we have let

$$
M_{1}=\tau x \int_{H\left[\varepsilon_{1}\right]}\left(\sum_{i=1}^{N} q_{i}^{*}\left[\theta \mid \varepsilon_{2}\right]\left(\theta_{i}-\frac{1-\Phi_{i}\left[\theta_{i}\right]}{\phi_{i}\left[\theta_{i}\right]}\right)\right) \prod_{j=1}^{N} \phi_{j}\left[\theta_{j}\right] d \theta_{N} \ldots d \theta_{1}
$$

and

$$
M_{2}=\tau x \int_{H\left[\varepsilon_{2}\right]-H\left[\varepsilon_{1}\right]}\left(\sum_{i=1}^{N} q_{i}^{*}\left[\theta \mid \varepsilon_{2}\right]\left(\theta_{i}-\frac{1-\Phi_{i}\left[\theta_{i}\right]}{\phi_{i}\left[\theta_{i}\right]}\right)\right) \prod_{j=1}^{N} \phi_{j}\left[\theta_{j}\right] d \theta_{N} \ldots d \theta_{1} .
$$

Now for each type profile $\theta=\left(\theta_{i}\right)_{i=1}^{N}$ in $H\left[\varepsilon_{2}\right]-H\left[\varepsilon_{1}\right]$, we have

$$
J_{i}\left[\theta_{i} \mid \varepsilon_{1}\right]=\varepsilon_{1}\left(1-\theta_{i}\right)+\tau\left(\theta_{i}-\frac{1-\Phi_{i}\left[\theta_{i}\right]}{\phi_{i}\left[\theta_{i}\right]}\right) \leq 0, \quad(i=1, \ldots, N) .
$$

Hence $\theta_{i}-\frac{1-\Phi_{i}\left[\theta_{i}\right]}{\phi_{i}\left[\theta_{i}\right]}<0$ for each $i=1, \ldots, N$, from which it follows that $M_{2}<0$.

Next, pick a type profile $\theta=\left(\theta_{i}\right)_{i=1}^{N}$ in $H\left[\varepsilon_{1}\right]$. Let $j$ be the firm that wins the bid when the weight of the welfare component is $\varepsilon_{1}$. We have

$$
\sum_{i=1}^{N} q_{i}^{*}\left[\theta \mid \varepsilon_{1}\right]\left(\theta_{i}-\frac{1-\Phi_{i}\left[\theta_{i}\right]}{\phi_{i}\left[\theta_{i}\right]}\right)=\theta_{j}-\frac{1-\Phi_{j}\left[\theta_{j}\right]}{\phi_{j}\left[\theta_{j}\right]} .
$$

Let $k$ be the firm that wins the bid when the weight of the welfare component is $\varepsilon_{2}$. We have 


$$
\sum_{i=1}^{N} q_{i}^{*}\left[\theta \mid \varepsilon_{2}\right]\left(\theta_{i}-\frac{1-\Phi_{i}\left[\theta_{i}\right]}{\phi_{i}\left[\theta_{i}\right]}\right)=\theta_{k}-\frac{1-\Phi_{k}\left[\theta_{k}\right]}{\phi_{k}\left[\theta_{k}\right]}
$$

If $j=k$, then

(B.6) $\sum_{i=1}^{N} q_{i}^{*}\left[\theta \mid \varepsilon_{1}\right]\left(\theta_{i}-\frac{1-\Phi_{i}\left[\theta_{i}\right]}{\phi_{i}\left[\theta_{i}\right]}\right)=\sum_{i=1}^{N} q_{i}^{*}\left[\theta \mid \varepsilon_{2}\right]\left(\theta_{i}-\frac{1-\Phi_{i}\left[\theta_{i}\right]}{\phi_{i}\left[\theta_{i}\right]}\right)$.

On the other hand, if $j \neq k$, then the following version of (B.2) must hold for firm $j$ and firm $k$ :

(B.7) $\varepsilon_{1}\left(1-\theta_{k}\right)+\tau\left(\theta_{k}-\frac{1-\Phi_{k}\left[\theta_{k}\right]}{\phi_{k}\left[\theta_{k}\right]}\right) \leq \varepsilon_{1}\left(1-\theta_{j}\right)+\tau\left(\theta_{j}-\frac{1-\Phi_{j}\left[\theta_{j}\right]}{\phi_{i}\left[\theta_{j}\right]}\right)$.

Furthermore, as in the proof of Claim 2, we have $\theta_{k}<\theta_{j}$, which together with (B.7) imply

$$
\theta_{k}-\frac{1-\Phi_{k}\left[\theta_{k}\right]}{\phi_{k}\left[\theta_{k}\right]}<\theta_{j}-\frac{1-\Phi_{j}\left[\theta_{j}\right]}{\phi_{i}\left[\theta_{j}\right]}
$$

That is, if $j \neq k$, then

(B.8) $\sum_{i=1}^{N} q_{i}^{*}\left[\theta \mid \varepsilon_{1}\right]\left(\theta_{i}-\frac{1-\Phi_{i}\left[\theta_{i}\right]}{\phi_{i}\left[\theta_{i}\right]}\right)>\sum_{i=1}^{N} q_{i}^{*}\left[\theta \mid \varepsilon_{2}\right]\left(\theta_{i}-\frac{1-\Phi_{i}\left[\theta_{i}\right]}{\phi_{i}\left[\theta_{i}\right]}\right)$.

Together, (B.6) and (B.8) imply that $M_{1} \leq \omega\left[\varepsilon_{1}\right]$. Thus $\omega\left[\varepsilon_{2}\right]<\omega\left[\varepsilon_{1}\right]$.

\section{APPENDIX C}

\section{ProOF OF PROPOSITION 5}

To study the influence of the percentage of cost awarded as profit on the optimal auction, we now make explicit the dependence of the marginal contribution of each firm on $\tau$ by writing it as

$$
J_{i}\left[\theta_{i} \mid \tau\right]=\varepsilon\left(1-\theta_{i}\right)+\tau\left(\theta_{i}-\frac{1-\Phi_{i}\left[\theta_{i}\right]}{\phi_{i}\left[\theta_{i}\right]}\right), \quad(i=1, \ldots, N)
$$


The value of $\theta_{i}$ that solves $J_{i}\left[\theta_{i} \mid \tau\right]=0$ is now noted $\theta_{i}^{+}[\tau]$, and the probability that a firm wins the bid under a type profile $\theta=\left(\theta_{i}\right)_{i=1}^{N}$ is now noted as $q_{i}^{*}[\theta \mid \tau], i=1, \ldots, N$.

Let $H[\tau]$ denote the set that consists of all type profiles $\theta=\left(\theta_{i}\right)_{i=1}^{N}$ such that $\theta_{i}>\theta_{i}^{+}[\tau]$ for some $i$. For a type profile $\theta \in H[\tau]$, the marginal contribution of at least one firm is positive, and $q_{i}^{*}[\theta \mid \tau]=1$ for some $i$. For a type profile $\theta \notin H[\tau]$, the marginal contribution of each firm is less than or equal to 0 and $q_{i}^{*}[\theta \mid \tau]=0$ for each $i=1, \ldots, N$.

CLAIM 1: A rise in the percentage of cost awarded as profit raises the threshold degree of inefficiency of each firm.

PROOF: According to the definition of $\theta_{i}^{+}[\tau]$, we have

(C.1) $J_{i}\left[\theta_{i}^{+}[\tau] \mid \tau\right]=\varepsilon\left(1-\theta_{i}^{+}[\tau]\right)+\tau\left(\theta_{i}^{+}[\tau]-\frac{1-\Phi_{i}\left[\theta_{i}^{+}[\tau]\right]}{\phi_{i}\left[\theta_{i}^{+}[\tau]\right]}\right)=0$

Because $\theta_{i}^{+}[\tau] \leq \bar{\theta}_{i}<1$, we must then have

(C.2) $\theta_{i}^{+}[\tau]-\frac{1-\Phi_{i}\left[\theta_{i}^{+}[\tau]\right]}{\phi_{i}\left[\theta_{i}^{+}[\tau]\right]}<0$, $(i=1, \ldots, N)$.

Now consider two values of $\tau$, say $\tau_{1}$ and $\tau_{2}$, with $0<\tau_{1}<\tau_{2}<1$. Using (C.1) and (C.2), we can write

(C.3) $J_{i}\left[\theta_{i}^{+}\left[\tau_{1}\right] \mid \tau_{2}\right]=\varepsilon\left(1-\theta_{i}^{+}\left[\tau_{1}\right]\right)+\tau_{2}\left(\theta_{i}^{+}\left[\tau_{1}\right]-\frac{1-\Phi_{i}\left[\theta_{i}^{+}\left[\tau_{1}\right]\right]}{\phi_{i}\left[\theta_{i}^{+}\left[\tau_{1}\right]\right]}\right)<0$.

Hence $\theta_{i}^{+}\left[\tau_{1}\right]<\theta_{i}^{+}\left[\tau_{2}\right]$; that is, a rise in the percentage of cost awarded as profit raises the threshold degree of inefficiency of each firm. 
ClAIM 2: A rise in the percentage of cost awarded as profit reduces social welfare.

PROOF: Using Claim 1, we can assert that $H\left[\tau_{2}\right] \subset H\left[\tau_{1}\right]$. Consider a profile of types $\theta=\left(\theta_{i}\right)_{i=1}^{N}$ in $H\left[\tau_{2}\right]$. Let $j$ be the firm that wins the bid under this profile of types when $\tau_{2}$ is the percentage of cost awarded as profit. In this case, the net social welfare is $x-\theta_{j} x$. For the same profile of types, if this firm also wins the bid when the percentage of cost awarded as profit is $\tau_{1}$, then the net social welfare does not change when the percentage of cost awarded as profit rises from $\tau_{1}$ to $\tau_{2}$. If a different firm, say firm $i$, wins the bid when the percentage of cost awarded as profit is $\tau_{1}$, then we must have

(C.4) $\varepsilon\left(1-\theta_{i}\right)+\tau_{1}\left(\theta_{i}-\frac{1-\Phi_{i}\left[\theta_{i}\right]}{\phi_{i}\left[\theta_{i}\right]}\right) \geq \varepsilon\left(1-\theta_{j}\right)+\tau_{1}\left(\theta_{j}-\frac{1-\Phi_{j}\left[\theta_{j}\right]}{\phi_{j}\left[\theta_{j}\right]}\right)$,

with $i<j$ when equality holds in (C.4). On the other hand, because firm $j$ wins the bid when the percentage of cost awarded as profit is $\tau_{2}$, the following inequality must also hold

(C.5) $\varepsilon\left(1-\theta_{i}\right)+\tau_{2}\left(\theta_{i}-\frac{1-\Phi_{i}\left[\theta_{i}\right]}{\phi_{i}\left[\theta_{i}\right]}\right) \leq \varepsilon\left(1-\theta_{j}\right)+\tau_{2}\left(\theta_{j}-\frac{1-\Phi_{j}\left[\theta_{j}\right]}{\phi_{i}\left[\theta_{j}\right]}\right)$,

with $j<i$ when equality holds in (C.5).

Because $i<j$ and $j<i$ cannot hold at the same time, either inequality (C.4) or inequality (C.5) must be strict. Subtracting (C.4) from (C.5), we obtain

$$
\left(\tau_{2}-\tau_{1}\right)\left(\theta_{i}-\frac{1-\Phi_{i}\left[\theta_{i}\right]}{\phi_{i}\left[\theta_{i}\right]}\right)<\left(\tau_{2}-\tau_{1}\right)\left(\theta_{j}-\frac{1-\Phi_{j}\left[\theta_{j}\right]}{\phi_{i}\left[\theta_{j}\right]}\right) .
$$

That is,

(C.6) $\theta_{i}-\frac{1-\Phi_{i}\left[\theta_{i}\right]}{\phi_{i}\left[\theta_{i}\right]}<\theta_{j}-\frac{1-\Phi_{j}\left[\theta_{j}\right]}{\phi_{i}\left[\theta_{j}\right]}$. 
Together, (C.4) and (C.6) imply $\theta_{i}<\theta_{j}$ : a rise in the percentage of cost awarded as profit lowers net social welfare.

CLAIM 3: A rise in the percentage of cost awarded as profit raises the expected remuneration of the retiring bureaucrat.

PROOF: When the percentage of cost awarded as profit is $\tau_{2}$, the expected remuneration of the retiring bureaucrat is given by

(C.7) $\omega\left[\tau_{2}\right]=\tau_{2} x \int_{H\left[\tau_{2}\right]}\left(\sum_{i=1}^{N} q_{i}^{*}\left[\theta \mid \tau_{2}\right]\left(\theta_{i}-\frac{1-\Phi_{i}\left[\theta_{i}\right]}{\phi_{i}\left[\theta_{i}\right]}\right)\right) \prod_{j=1}^{N} \phi_{j}\left[\theta_{j}\right] d \theta_{N} \ldots d \theta_{1}$.

When the percentage of cost awarded as profit is $\tau_{1}$, the expected remuneration of the retiring bureaucrat - according to (6) - is given by

$$
\begin{gathered}
\omega\left[\tau_{1}\right]=\tau_{1} x \int_{H\left[\tau_{1}\right]}\left(\sum_{i=1}^{N} q_{i}^{*}\left[\theta \mid \tau_{1}\right]\left(\theta_{i}-\frac{1-\Phi_{i}\left[\theta_{i}\right]}{\phi_{i}\left[\theta_{i}\right]}\right)\right) \prod_{j=1}^{N} \phi_{j}\left[\theta_{j}\right] d \theta_{N} \ldots d \theta_{1} \\
=M_{1}+M_{2}
\end{gathered}
$$

where we have let

$$
M_{1}=\tau_{1} x \int_{H\left[\tau_{2}\right]}\left(\sum_{i=1}^{N} q_{i}^{*}\left[\theta \mid \tau_{1}\right]\left(\theta_{i}-\frac{1-\Phi_{i}\left[\theta_{i}\right]}{\phi_{i}\left[\theta_{i}\right]}\right)\right) \prod_{j=1}^{N} \phi_{j}\left[\theta_{j}\right] d \theta_{N} \ldots d \theta_{1},
$$

and

$$
M_{2}=\tau_{1} x \int_{H\left[\tau_{1}\right]-H\left[\tau_{2}\right]}\left(\sum_{i=1}^{N} q_{i}^{*}\left[\theta \mid \tau_{1}\right]\left(\theta_{i}-\frac{1-\Phi_{i}\left[\theta_{i}\right]}{\phi_{i}\left[\theta_{i}\right]}\right)\right) \prod_{j=1}^{N} \phi_{j}\left[\theta_{j}\right] d \theta_{N} \ldots d \theta_{1} .
$$

Now for each type profile $\theta=\left(\theta_{i}\right)_{i=1}^{N}$ in $H\left[\varepsilon_{1}\right]-H\left[\varepsilon_{2}\right]$, we have

$$
J_{i}\left[\theta_{i} \mid \tau_{2}\right]=\varepsilon\left(1-\theta_{i}\right)+\tau_{2}\left(\theta_{i}-\frac{1-\Phi_{i}\left[\theta_{i}\right]}{\phi_{i}\left[\theta_{i}\right]}\right) \leq 0, \quad(i=1, \ldots, N)
$$

Hence $\theta_{i}-\frac{1-\Phi_{i}\left[\theta_{i}\right]}{\phi_{i}\left[\theta_{i}\right]}<0$ for each $i=1, \ldots, N$, and this implies $M_{2}<0$. 
Next, pick a type profile $\theta=\left(\theta_{i}\right)_{i=1}^{N}$ in $H\left\{\varepsilon_{2}\right\}$. Let $j$ be the firm that wins the bid when the percentage of cost awarded as profit is $\tau_{2}$. We have

$$
\sum_{i=1}^{N} q_{i}^{*}\left[\theta \mid \tau_{2}\right]\left(\theta_{i}-\frac{1-\Phi_{i}\left[\theta_{i}\right]}{\phi_{i}\left[\theta_{i}\right]}\right)=\theta_{j}-\frac{1-\Phi_{j}\left[\theta_{j}\right]}{\phi_{j}\left[\theta_{j}\right]} .
$$

Let $k$ be the firm that wins the bid when the percentage of cost awarded as profit is $\tau_{1}$. We have

$$
\sum_{i=1}^{N} q_{i}^{*}\left[\theta \mid \tau_{1}\right]\left(\theta_{i}-\frac{1-\Phi_{i}\left[\theta_{i}\right]}{\phi_{i}\left[\theta_{i}\right]}\right)=\theta_{k}-\frac{1-\Phi_{k}\left[\theta_{k}\right]}{\phi_{k}\left[\theta_{k}\right]}
$$

If $j=k$, then

$$
\text { (C.9) } \sum_{i=1}^{N} q_{i}^{*}\left[\theta \mid \tau_{1}\right]\left(\theta_{i}-\frac{1-\Phi_{i}\left[\theta_{i}\right]}{\phi_{i}\left[\theta_{i}\right]}\right)=\sum_{i=1}^{N} q_{i}^{*}\left[\theta \mid \tau_{2}\right]\left(\theta_{i}-\frac{1-\Phi_{i}\left[\theta_{i}\right]}{\phi_{i}\left[\theta_{i}\right]}\right) \text {. }
$$

On the other hand, if $j \neq k$, then the following inequality must hold because firm $j$ wins the bid when $\tau_{2}$ is the percentage of cost awarded as profit:

(C.10) $\varepsilon\left(1-\theta_{k}\right)+\tau_{2}\left(\theta_{k}-\frac{1-\Phi_{k}\left[\theta_{k}\right]}{\phi_{k}\left[\theta_{k}\right]}\right) \leq \varepsilon\left(1-\theta_{j}\right)+\tau_{2}\left(\theta_{j}-\frac{1-\Phi_{j}\left[\theta_{j}\right]}{\phi_{i}\left[\theta_{j}\right]}\right)$.

Furthermore, as in the proof of Claim 2, we have $\theta_{k}<\theta_{j}$, which together with (C.10) imply

$$
\theta_{k}-\frac{1-\Phi_{k}\left[\theta_{k}\right]}{\phi_{k}\left[\theta_{k}\right]}<\theta_{j}-\frac{1-\Phi_{j}\left[\theta_{j}\right]}{\phi_{i}\left[\theta_{j}\right]}
$$

That is, if $j \neq k$, then

(C.11) $\sum_{i=1}^{N} q_{i}^{*}\left[\theta \mid \tau_{1}\right]\left(\theta_{i}-\frac{1-\Phi_{i}\left[\theta_{i}\right]}{\phi_{i}\left[\theta_{i}\right]}\right) \leq \sum_{i=1}^{N} q_{i}^{*}\left[\theta \mid \tau_{2}\right]\left(\theta_{i}-\frac{1-\Phi_{i}\left[\theta_{i}\right]}{\phi_{i}\left[\theta_{i}\right]}\right)$.

Together, (C.9) and (C.11) imply that $M_{1} \leq \omega\left[\tau_{2}\right]$. Thus $\omega\left[\varepsilon_{2}\right]>\omega\left[\varepsilon_{1}\right]$. 


\section{REFERENCES}

AIDT T. S. (2003) Economic Analysis of Corruption: A Survey. The Economic Journal 113, F632-F652.

ASANO, A., and T. ETO (2003) The Game Theoretic Analysis of the Amakudari

Practice in the Japanese Banking System. Australian National University Working Paper, No. 434.

ASANO, A., and T. ETO (2005a) Amakudari as a Signal: Possible Malfunctioning of the Amakudari Practice under the Limited Deposit Insurance System. Japan Forum 17, 335-345.

ASANO, A., and T. ETO (2005b) The Paradox of Limited Deposit Insurance under the Amakudari Practice in the Japanese Banking System. Journal of Asian Economics 17,126-143.

BERGSTROM, T., and M. BAGNOLI (2005) Log-concave Probability and its Applications. Economic Theory 26, 445-469.

BULOW, J., and J. ROBERTS (1989) The Simple Economics of Optimal Auctions. Journal of Political Economy 97, 1060-1090.

CALDER, K. E. (1989) Elites in an Equalizing Role: Ex-Bureaucrats as Coordinators and Intermediaries in the Japanese Government-Business Relationship. Comparative Politics 21, 379-403.

COLIGNON, R. A., and C. USUI (2003) Amakudari: The Hidden Fabric of Japan's Economy. New York: Cornell University Press.

DRUCKER, P. F. (1998) In Defense of Japanese Bureaucracy. Foreign Affairs 77, 68- 80 .

EDWARDS, F. R. (1977) Managerial Objectives in Regulated Industries:

Expense-Preference Behavior in Banking Journal of Political Economy 85, 147-162.

GROSSMAN, G. M., and E. HELPMAN (2001) Special Interest Politics. Cambridge: The MIT Press.

HORIUCHI, A., and K. SHIMIZU (2001) Did Amakudari Undermine the Effectiveness of Regulator Monitoring in Japan? Journal of Banking \& Finance 25, 573-596. 
JOHNSTON, M. (2005) Syndromes of Corruption. New York: Cambridge University Press.

KOMIYA, R., M. OKUNO, and K. SUZUMURA, ed. (1988) Industrial Policy of Japan. Tokyo, Japan: Academic Press.

MAS-COLELL, A., M. D. WHINSTON, and J. R. GREEN (1995) Microeconomic Theory. New York: Oxford University Press.

MYERSON, R. B. (1981) Optimal Auction Design. Mathematics of Operation Research 6, 58-73.

Suzuki, K. (2004) The Changing Pattern of Amakudari Appointments - The Case of Regional Banks, 1991-2000. The European Institute of Japanese Studies, EIJS Working Paper Series, No. 187.

RIXTEL, A. V. (2002) Informality and Monetary Policy in Japan. Cambridge: Cambridge University Press.

Yamori, N. (1998) Bureaucrat-Managers and Corporate Governance: ExpensePreference Behaviors in Japanese Financial Institutions. Economics Letters 61, 385-389. 